\title{
A INFLUÊNCIA DA OUVIDORIA COMO FERRAMENTA DE GESTÃO ESTRATÉGICA
}

\author{
Helizena Celestino da Silva ${ }^{1}$
}

\begin{abstract}
Resumo
O presente trabalho discorre sobre a influência da Ouvidoria na empresa enquanto ferramenta de gestão estratégica, provocando mudanças em processos a partir das informações obtidas por intermédio das demandas registradas independentemente da procedência da manifestação e da natureza do assunto apontado pelo usuário. Tomando como base as experiências no exercício da função de Ouvidora de instituições de segmentos diversos, o artigo traz relatos de experiências que ilustram ações de proatividade realizadas pela equipe da Ouvidoria, a postura dos gestores e colaboradores das instituições diante das sugestões apresentadas e os resultados obtidos. Apresenta situações ocorridas em Ouvidoria de Hospital Geral e Concessionária de Rodovias. A atividade foco do trabalho é destacar a importância da Ouvidoria enquanto ferramenta de gestão estratégica e a necessidade da adoção de postura proativa de parte do Ouvidor para colocar em evidência aquilo que merece destaque e atenção da alta administração (diretoria, coordenadores e supervisores) e promover ações para disseminar a cultura do amplo diálogo na instituição e de estreitar o relacionamento com as diversas áreas, demonstrando que a Ouvidoria é responsável pela recepção, organização e fortalecimento de um conjunto de informações imprescindíveis para a tomada de decisões que reverterão em melhores resultados por ouvir, acolher e considerar a expectativa e percepção do cliente. A base teórica utilizada na pesquisa explorou dados encontrados em bibliografias que versam sobre Ouvidoria, Administração e Gestão Estratégica. A metodologia utilizada é a atuação profissional no decorrer de onze anos em Ouvidorias do setor financeiro, saúde e concessão de serviço público. O resultado do trabalho é a apresentação de relatos de experiências com situações em que melhorias nos processos foram propostas à organização a partir da análise minuciosa de indicadores e ações de divulgação dos princípios da Ouvidoria aos responsáveis pelas áreas, bem como o acompanhamento do processo de atendimento operacional da concessionária para sugestão de melhorias, deixando como proposta ao leitor o convite para demonstrar à diretoria da instituição em que trabalha a expectativa e a percepção do cliente e propor melhorias.
\end{abstract}

Palavras-chave: Ouvidoria. Gestão estratégica. Melhoria. Proatividade.

DOI:10.37814/2594-5068.2020v3.p79-91

1 Ouvidora certificada pela ABO, atuando em Ouvidoria desde 2008. Técnica em marketing, graduada em Administração de Empresas, pós-graduada em Gestão Estratégica de Negócios - Unesp Bauru e auditora líder com certificação RAC (ISO9001/2015). (helizena@yahoo.com.br) 


\begin{abstract}
This paper discusses the influence of the Ombudsman on the company as a tool for strategic management, provoking changes in processes based on the information obtained through the demands registered regardless of the origin of the manifestation and the nature of the subject pointed out by the user. Based on the experiences in the exercise of the Ombudsman function of institutions of different segments, the article presents experiences that illustrate proactivity actions carried out by the Ombudsman's team, the attitude of the managers and collaborators of the institutions regarding the suggestions presented and the results obtained. It presents situations occurred in Ombudsman's Office of General Hospital and Concessionary of Highways. The focus of the work is to highlight the importance of the Ombudsman's Office as a strategic management tool and the need to adopt a proactive stance on the part of the Ombudsman to highlight what deserves focus and attention from top management (board, coordinators and supervisors) and promote actions to disseminate the culture of the broad dialogue in the institution and to strengthen the relationship with the various institutions, demonstrating that the Ombudsman's Office is responsible for the reception, organization and strengthening of a set of information essential for making decisions that will focus on better results by listening, accept and consider the client's expectations and perceptions. The theoretical basis used in the research explored data found in bibliographies dealing with Ombudsman, Administration and Strategic Management. The methodology used is the professional performance during eleven years in Ombudsman of the financial sector, health and public service concession. The result of the work is the presentation of reports of experiences with situations in which improvements in the processes were proposed to the organization based on a detailed analysis of indicators and actions to disseminate the Ombudsman principles to those responsible for the areas, as well as the monitoring of the process of the concessionaire's operational service to suggest improvements, leaving as a proposal to the reader the invitation to demonstrate to the board of the institution where the client's expectation and perception works and propose improvements.
\end{abstract}

Keywords: Ombudsman. Strategic management. Improvement. Proactivity. 


\section{INTRODUÇÃO}

A relação entre a Ouvidoria e as demais áreas da empresa, as eventuais dificuldades nessa relação compreendidas na ausência de entendimento e na não utilização da Ouvidoria como ferramenta de gestão estratégica são fatores comuns nos segmentos diversos e frequentemente fatores causadores de "paralisia parcial" da Ouvidoria, que muitas vezes tem a atuação como mero canal de comunicação, trabalhando de forma reativa, sem nenhuma performance estratégica (Ouvidoria de bombeiro). O desafio de transformar essa realidade, alcançando maior legitimidade, agindo preventivamente e assumindo o papel essencial dentro da organização, é a origem do tema abordado no presente artigo que dispõe ainda sobre os objetivos, as limitações e a metodologia adotada para o desenvolvimento do trabalho no intuito de proporcionar ao leitor, seja ele um profissional dessa área de atuação, gestor ou estudante, o entendimento de que a Ouvidoria é mais do que meramente um canal de comunicação e sim uma importante ferramenta de gestão estratégica.

\subsection{Origem do Tema}

Atuar na área de Ouvidoria é um grande desafio, pois trata-se de atividade especifica na qual o nível de complexidade precisa ser compreendido claramente por toda a organização. Quando esse entendimento não ocorre, a Ouvidoria fica limitada a atuação apenas na vertente operacional - canal restrito à comunicação, desperdiçando a vertente gerencial - como ferramenta de gestão estratégica.

$\mathrm{Na}$ qualidade de profissional atuante em Ouvidoria desde 2008 em segmentos diferentes (assessoria jurídica, hospital geral e concessionária de rodovias), com experiência em desenvolvimento de projeto e implantação, bem como em reestruturação, além de ter realizado trabalho de disseminação da cultura do instituto da Ouvidoria nas organizações, posso afirmar que um fato notório e comum a todas as instituições é a ausência do real entendimento das áreas, sobre sua função e importância, seja entre gestores ou colaboradores administrativos e operacionais.

O entendimento equivocado, ou melhor, limitado quanto à função da área é fator determinante para o estabelecimento de "muros" entre a Ouvidoria e os gestores das demais áreas, reduzindo significativamente a possibilidade de atuação na melhoria dos processos, por consequência nos resultados da instituição e na melhor qualidade de relacionamento com o cliente.

O objeto do presente artigo é a influência da Ouvidoria enquanto ferramenta de gestão estratégica, sendo imprescindível atentar ao relacionamento dessa com as demais áreas da organização. A ideia é produzir um artigo que apresenta sugestões sobre como aproximar a Ouvidoria das demais áreas. $\mathrm{O}$ artigo cita situações em que foram realizadas ações que proporcionaram à organização o entendimento sobre a real função da Ouvidoria, a aproximação com os gestores, quebra de paradigmas e melhorias efetivas nos processos que incidiram no grau de satisfação dos clientes. A proposta do presente artigo implica ainda auxiliar os Ouvidores no exercício de suas funções quanto ao atendimento da legislação, no tocante à exigência de que o Ouvidor faça recomendações de mudanças e práticas de aperfeiçoamento ao dirigente máximo da organização para otimização de 
resultados. Segundo disposto no Decreto $\mathrm{n}^{\circ} 60.399$ em seu capítulo III, seção I, artigo $4^{\circ}$, parágrafos XIII e XIV, a Ouvidoria deve fazer recomendações para a melhoria da qualidade dos serviços prestados, sugerindo soluções de problemas, correção de erros, omissões ou abusos cometidos; promover sensibilização sobre as atividades da Ouvidoria no órgão ou entidade em que atua, observando o que se segue no parágrafo único: "As recomendações de que trata o inciso XIII deste artigo devem ser encaminhadas formalmente, com suas respectivas justificativas, à autoridade máxima do órgão ou entidade em que atuam".

\subsection{Formulação do Problema}

Qual o fator determinante para a utilização precária da Ouvidoria como ferramenta de gestão estratégica nas organizações?

\subsection{Justificativa}

A necessidade da existência de métodos definidos para que a Ouvidoria atue efetivamente como ferramenta de gestão estratégica, a limitada produção técnica e científica sobre o instituto Ouvidoria e a ausência de literaturas específicas sobre a importância de atuação nas organizações que apontem, com objetividade, as atribuições da Ouvidoria formam o conjunto de elementos determinantes para a elaboração do presente trabalho.

\section{REFERENCIAL TEÓRICO}

\subsection{Função do Ouvidor}

A origem da figura do Ombudsman é europeia. No Brasil, em 1986, o jornal Folha de S.Paulo, se espelhando no jornal espanhol El País, o qual tinha como um modelo a seguir, tomou a decisão de instituir um representante do leitor, surgindo então o primeiro Ombudsman brasileiro, o jornalista Caio Túlio Costa.

Embora o primeiro Ouvidor brasileiro, no período republicano, tenha sido instituído em 1986, a função do Ouvidor só passou a compor a lista de profissões classificadas em fevereiro de 2013, quando o Ministério do Trabalho e Emprego estabeleceu pela Classificação Brasileira de Ocupação, sob o código 1423-40, a função de Ouvidor como pertencente ao segmento de gerentes de comercialização, marketing e comunicação, definindo perfil, atividades e atribuições do profissional de Ouvidoria. As definições da CBO no tocante às funções de Ouvidoria contaram com a contribuição da Associação Brasileira de Ouvidores - ABO, que desde o início de sua trajetória apresenta o código de ética e o decálogo do Ouvidor, documentos que norteiam a conduta dos profissionais de Ouvidoria. 
No material disponibilizado pela Classificação Brasileira de Ocupação encontra-se a seguinte descrição sumária da família de profissões na qual a função de Ouvidor foi inserida:

Elaboram planos estratégicos das áreas de comercialização, marketing e comunicação para empresas agroindustriais, industriais, de comercialização e serviços em geral; implementam atividades e coordenam sua execução; assessoram a diretoria e setores da empresa. $\mathrm{Na}$ área de atuação, gerenciam recursos humanos, administram recursos materiais e financeiros e promovem condições de segurança, saúde, preservação ambiental e qualidade.

No documento classificatório de ocupações encontra-se descrita a atividade de elaboração do plano estratégico das áreas de negócio e relacionamentos, onde se destacam, entre as subatividades do Ouvidor, a elaboração de recomendações de ações e soluções, bem como a detecção de expectativas e necessidades.

\section{QUADRO $1-1^{\text {a }}$ Atividade Principal}

\begin{tabular}{|l|l|}
\hline Atividade & A-Elaborar plano estratégico das áreas de negócios e relacionamentos \\
\hline \multirow{5}{*}{ Subatividades } & Estabelecer políticas e procedimentos de comunicação \\
\cline { 2 - 3 } & Estabelecer política comercial \\
\cline { 2 - 3 } & Pesquisar mercado \\
\cline { 2 - 3 } & Analisar tendências do mercado \\
\cline { 2 - 3 } & Enalisar fatores econômico-financeiros \\
\cline { 2 - 3 } & Planejar ações para promoção da imagem institucional \\
\cline { 2 - 3 } & Planejar campanhas publicitárias \\
\cline { 2 - 3 } & Planejar campanhas de vendas \\
\cline { 2 - 3 } & Planejar eventos (feiras, convenções, congressos, seminários) \\
\cline { 2 - 3 } & Identificar necessidades de recursos \\
\cline { 2 - 3 } & Elaborar orçamentos \\
\cline { 2 - 3 } & Planejar racionalização do uso de recursos \\
\cline { 2 - 3 } & Revisar planos \\
\cline { 2 - 3 } & Detectar expectativas e necessidades \\
\cline { 2 - 3 } & Pesquisar comportamentos, opiniões e hábitos \\
\cline { 2 - 3 } & Analisar contexto \\
\cline { 2 - 3 } & Elaborar recomendações de ações e soluções \\
\hline
\end{tabular}

Fonte: Classificação Brasileira de Ocupações (2014) 


\subsection{COMUNICAÇÃO/RELACIONAMENTO COM AS ÁREAS E DISSEMINAÇÃO DA CULTURA DE OUVIDORIA}

Embora a comunicação possa acontecer utilizando apenas gestos ou expressões faciais, sem a emissão de nenhuma palavra, conseguir estabelecê-la de forma plena, em que a mensagem seja entendida pelo receptor de modo fidedigno como fora enviada pelo emissor, é uma tarefa difícil. No caso da comunicação da Ouvidoria com as demais áreas da organização há ainda um ponto desfavorável, a ideia equivocada de que a Ouvidoria é "inimiga", pois está sempre apontando os problemas das áreas que são reconhecidos por meio das manifestações dos clientes.

O paradigma ainda existente na percepção de alguns gestores de que a Ouvidoria atua de modo adversário, estabelecendo dessa forma uma barreira no relacionamento com as áreas da organização, é um entendimento equivocado que pode causar impactos negativos inclusive na qualidade de subsídios oferecidos pelas áreas à Ouvidoria, pois, com o intuito de protegerem suas unidades administrativas, alguns gestores oferecem respostas evasivas, incompletas ou com informações divergentes, causando morosidade na análise da demanda e em alguns casos induzindo respostas equivocadas.

Transformar o paradigma de que a Ouvidoria apenas aponta os problemas das áreas é o primeiro passo para melhorar o relacionamento e com isso facilitar a comunicação.

Como case exitoso é válido mencionar a experiência vivenciada na Ouvidoria de um hospital geral. Durante o processo de implantação dessa área, uma das etapas foi o trabalho de disseminação da cultura de Ouvidoria, adotando-se uma metodologia de comunicação que compreendia visita da Ouvidora às áreas, com realização de palestras para os demais colaboradores e o envio de comunicados internos esclarecendo temas básicos como: o que é Ouvidoria, para que serve, quando e como deve ser acionada, diferenças entre primeira instância e segunda instância; e, em um segundo momento, diante de resistências estabelecidas pelas áreas de maior demanda que se sentiam "ameaçadas" pelos apontamentos da Ouvidoria e propositadamente "dificultavam o acesso às informações", foram realizadas reuniões pontuais com os gestores resistentes, apresentando a eles a Ouvidoria como ferramenta de gestão estratégica a fim de estabelecer uma relação de parceria, demonstrando que as demandas registradas e os apontamentos realizados pela Ouvidoria poderiam ser utilizados para melhoria dos processos, sobretudo em razão da riqueza de detalhes e informações existentes nessas manifestações e a facilidade de utilizá-las para determinar ações preventivas, reduzindo dessa forma o volume de problemas e otimizando resultados.

A reação dos gestores ao compreender a Ouvidoria como aliada foi extremamente positiva, pois as resistências e o receio de oferecer à Ouvidora os subsídios para análise das demandas deu lugar a uma postura proativa, optando diversas vezes por procurar pela Ouvidoria para solicitar relatórios e análises de situações no intuito de entender a causa das insatisfações, mesmo quando elas não representavam incorreções e anomalias no procedimento.

Há ainda outro fator determinante para o alcance da legitimidade da Ouvidoria: o desafio de obter o total apoio do líder máximo da organização. Uma vez que as áreas passam a compreender a Ouvidoria como aliada pela atividade de gestão que promove indicadores para balizar a tomada

84 | Revista Científica da Associação Brasileira de Ouvidores/Ombudsman - Ano 3 - n $3-2020$ 
de decisões e percebem o envolvimento e confiança do líder máximo da organização em relação à Ouvidoria, o sucesso na comunicação e relacionamento com as áreas está garantido.

\subsection{Gestão Estratégica}

Segundo Maximiano, o conceito de gestão estratégica é originário do mundo militar, onde ela era entendida como uma política imaginada para reduzir e controlar incertezas, atualmente vista como método, abordagem ou maneira de agir, ou ainda caminho (MAXIMIANO, 2012, p. 335).

Partindo desse conceito e relacionando estratégia à atuação da Ouvidoria, pode se dizer que as informações obtidas por meio das manifestações de satisfação e insatisfação dos usuários, quando convertidas em indicadores, representam uma fotografia da organização sob a ótica do cliente e, a partir disso, é possível definir o caminho a ser seguido para reforçar aquilo que é bom ou melhorar o que aos seus olhos, independentemente de estar ou não atendendo aos padrões de normas e legislações, causa uma percepção negativa sobre a instituição.

As Ouvidorias são capazes de estruturar e produzir informações e estatísticas acerca do desempenho de atividades, produtos e serviços, gerando recomendações quanto às políticas a serem adotadas e fornecendo subsídios para a alta administração na reestruturação dos processos (SERTEK; GUINDANI; MARTINS, 2011, p. 120).

O alinhamento entre Ouvidoria e gestores das áreas é fator imprescindível para o sucesso da gestão estratégica, cabendo ao Ouvidor desenvolver a capacidade de analisar minuciosamente os indicadores, observando ponto a ponto cada detalhe, pois é dessa forma que o cliente olha, e uma das missões do Ouvidor é enxergar com os olhos do cliente.

O consumidor ciente de seus direitos, do seu poder de escolha, da sua importância para as empresas e preocupado com questões como meio ambiente, responsabilidade social e preservação dos animais, assumiu um novo papel: o de contribuir para a melhoria das organizações (SILVA, HELIZENA CELESTINO, 2014)

$\mathrm{Na}$ análise de indicadores é importante estar atento a dois fatores: quantidade de ocorrências e relevância, pois, um assunto aparentemente de baixa relevância quando ocorre repetidas vezes torna-se tão importante quanto um assunto de extrema relevância ocorrido uma única vez.

A Ouvidoria desponta como a mais nova ferramenta de gestão estratégica da qualidade: tem contato direto com a percepção do cliente, cria indicadores que apontam não só os processos que podem ou devem ser melhorados, mas indicam pontualmente o sub processo/atividade a ser verificado e atua junto aos gestores e diretores da organização nas ações para melhoria dos processos (SILVA, 2014).

Ao identificar os pontos importantes, seja em razão da quantidade ou da relevância do assunto, o Ouvidor deve atentar ao fluxo do processo em evidência, avaliando cada passo do fluxograma no intuito de trazer à tona o "gargalo" - ponto do processo onde há uma anomalia/necessidade de melhoria.

Quando o Ouvidor consegue explorar o fluxograma do processo e identificar o "calcanhar de Aquiles" da organização, ele é capaz de fornecer aos gestores mais do que simplesmente núme- 
ros em um indicador, e sim a causa raiz da situação, acrescida de sugestões para resolução. Vale observar que a decisão quanto à ação a ser tomada sempre será do gestor da área, no entanto, a informação apresentada pela Ouvidoria, com embasamento sólido, poderá promover agilidade na tomada de decisões e um percentual de assertividade expressivo.

Torna-se óbvio, na conjuntura imposta pelo mercado do terceiro milênio, que as organizações devem, necessariamente, apresentar maior capacidade de resposta às solicitações do meio em função de uma condição de maior competitividade (SERTEK; GUINDANI; MARTINS, 2011, p. 51).

\section{PROCEDIMENTOS METODOLÓGICOS}

A metodologia utilizada para elaboração do artigo teve como base a revisão bibliográfica, o conhecimento e a experiência adquiridos em onze anos de atuação em Ouvidoria e os cases vivenciados pela autora durante a atuação em Ouvidoria de segmentos distintos (assessoria jurídica, hospital geral e concessionária de rodovias). A revisão bibliográfica explorou os temas: função do Ouvidor utilizando como referencial o descritivo da CBO (Classificação Brasileira de Ocupações), comunicação/relacionamento com as áreas e disseminação da cultura de Ouvidoria, nesse tema o referencial foi a experiência da autora e a monografia produzida na ocasião da conclusão do curso de pós-graduação em Gestão Estratégica.

As fontes de pesquisa foram livros de autoria de nomes expressivos no campo da administração, as legislações pertinentes à Ouvidoria e os conteúdos desenvolvidos no trabalho de monografia de pós-graduação da autora, cuja relevância se faz presente em razão da justificada experiência adquirida ao longo da atuação em Ouvidoria de três segmentos distintos: área financeira (assessoria jurídica - cobrança), área da saúde (hospital geral - saúde privada) e área de concessão de serviço público (concessionária de rodovias). Durante dois anos de atuação na Ouvidoria de uma organização do segmento financeiro, os conhecimentos adquiridos sobre processo operacional da área, elaboração de relatórios e análise de dados serviram de base para a formação, possibilitando, posteriormente, assumir o desafio de desenvolver e implantar um projeto de Ouvidoria em um hospital privado. Durante os três anos de atuação foi possível acompanhar várias situações de meIhorias promovidas pelas informações adquiridas na Ouvidoria, incluindo a análise minuciosa dos indicadores e apresentando recomendações de mudanças/aperfeiçoamento dos processos vigentes. O terceiro segmento que contribuiu para o enriquecimento do conteúdo do artigo foi a atuação desde 2015 em concessão de serviço público, na Ouvidoria de Concessionária de Rodovias, e a oportunidade de reestruturar o funcionamento dessa área, estabelecida na instituição desde a sua fundação. Nessa experiência foi possível reviver dificuldades conhecidas por ocasião da implantação de uma Ouvidoria, além de ter adquirido novos conhecimentos quanto às necessidades e dificuldades para sua plena atuação como canal de comunicação e ferramenta de gestão estratégica.

O produto final do presente artigo são cases apresentados de forma rápida e simples com o objetivo de exemplificar e reiterar a afirmação de que o trabalho da Ouvidoria pode trazer melhores resultados para a organização e representar expressiva diferença ao deixar de ser apenas reativa (Ouvidoria de bombeiro) e agir proativamente, analisando a fundo os indicadores independente-

86 | Revista Científica da Associação Brasileira de Ouvidores/Ombudsman - Ano 3 - n 3 - 2020 
mente de representarem situações procedentes ou improcedentes, e sim considerando que, se há algo que na percepção do cliente está incomodando, então há algo passível de melhoria.

Os cases apresentados ocorreram nas Ouvidorias citadas, com base nos princípios e regras dispostos no Código de Ética proposto pela Associação Brasileira de Ouvidores, bem como respeitando as legislações pertinentes e os procedimentos das organizações.

\section{RESULTADOS}

A rotina de um Hospital Geral da iniciativa privada não apresenta a constante e numerosa problemática relativa à demora no atendimento e falta de leitos vivenciada pela saúde pública, no entanto, alguns casos esporádicos podem ser registrados na Ouvidoria. Logo no início das atividades da Ouvidoria implantada nesse hospital, assuntos relativos à demora no atendimento do Pronto Atendimento representavam a maior parte das insatisfações registradas: importante observar que à época (2010) os prontuários médicos eram documentos físicos e de preenchimento manual, o que dificultava o "monitoramento" do tempo de espera para o atendimento. Em contato com os responsáveis para análise das insatisfações, o esclarecimento era que, no tocante à demora no atendimento, se observado o tempo estimado segundo a classificação de risco, temos: atendimento imediato para emergência (cor vermelha), até 30 minutos para urgência (amarelo), até 1 hora para semiurgência (verde) e até 2 horas para não urgência (azul). Sendo assim, avaliando sob a ótica da classificação de risco, o que se observava era que muitas reclamações eram improcedentes (considerando o quadro clinico apresentado e a classificação de risco), no entanto, o alto volume de reclamações despertou na Ouvidora a necessidade de compreender o fator desencadeante da sua ocorrência, motivando uma análise minuciosa do processo de atendimento no Pronto Atendimento.

A primeira situação observada é que a classificação de risco não era algo evidenciado e expresso para os pacientes, por isso muitas vezes a ausência de previsão e conhecimento do tempo estimado de espera acabava por provocar a sensação de demora. Por procedimento, a classificação de risco é realizada previamente na triagem, logo que o paciente chega à unidade de Pronto Atendimento, mas isso não era passado para ele. A partir de então, a triagem com identificação da classificação de risco foi instituída de forma mais organizada e regimental e, na recepção do Pronto Atendimento, foi afixada uma placa informativa sobre a classificação de risco.

Outro ponto identificado era que algumas vezes ocorriam reclamações de demora procedentes, em ocasiões em que não havia grande volume de pacientes aguardando por atendimento, o que era no mínimo curioso. Ainda imbuída na busca de esclarecimentos e resolutividade para os problemas apontados e por entender que a insatisfação dos pacientes independentemente do índice de procedência é um indicador de que há algo a ser melhorado, por um período de vinte dias corridos, a Ouvidora levantou uma amostra aleatória de atendimentos, segmentados por tipo (infantil, adulto e ortopedia), e avaliou, em cada um desses atendimentos, os intervalos de tempo (recepção - triagem - atendimento médico - exames - resultado de exame e reavaliação - medicação e alta). Com essa análise foi possível identificar os horários e dias da semana de pico, para cada tipo de atendimento, sugerindo alterações no número de plantonistas. A sugestão foi acatada pelos 
gestores e houve significativa diminuição do número de reclamações por tempo de espera para o cliente ser consultado. Outro aspecto importante foi a identificação de que a recepção e a triagem eram realizadas com celeridade, no entanto, pelo fato de as fichas de pacientes adultos e infantis permanecerem misturadas, ocorriam situações em que um paciente pediátrico ficava muito tempo aguardando em razão de sua ficha estar posicionada no final e, como resultado, o médico ficava ocioso enquanto a criança aguardava pelo atendimento durante mais tempo do que o necessário. Assim foi sugerida a separação da estrutura do Pronto Atendimento infantil e adulto e a criação de um ambiente mais adequado às crianças no PA Infantil. As sugestões foram acatadas, e na TV da Recepção Infantil passaram a ser disponibilizados somente canais de programas infantis, tornando o ambiente mais propício a esse público.

Outro aspecto detectado em algumas reclamações sobre demora no atendimento era o fato de o paciente relatar a longa espera e atribuí-la à obtenção do resultado do exame de sangue. A Ouvidoria, no exercício de suas atribuições, solicitou informações aos responsáveis e, analisando os registros do laboratório, constatou que o tempo entre a entrada do material e a saída do resultado estava dentro do previsto. Objetivando atuar na detecção do problema e na colaboração da construção conjunta de uma solução, foi feita a análise pontual dos tempos de atendimento de cada etapa realizada no Pronto Atendimento. Esse estudo permitiu identificar que a causa da demora encontrava-se na logística de entrega do material (sangue) ao laboratório. A Ouvidora, detentora dessas análises, registros e informações, sugeriu a revisão e, posteriormente, foi implantada a melhoria que alcançou bons resultados.

O segundo maior índice de registro de reclamações no hospital era relativo à falta de leitos, que, no entendimento da diretoria, se tratava de um problema de estrutura, que só poderia ser resolvido com a construção de mais quartos. A Ouvidoria realizou o estudo do fluxograma do processo de internação, considerando os dois tipos de entrada existentes: emergência (quando a entrada era através do Pronto Atendimento) e eletiva (quando o procedimento era agendando previamente), além de considerar a expectativa e percepção dos pacientes para a realização de proposta de melhoria. Foi identificado que os pacientes que aguardavam na recepção para serem internados e submetidos a cirurgia eletiva, ao permanecer muito tempo na recepção, eram expostos a uma "tortura silenciosa", pois se encontravam em jejum alimentar e ficavam sentindo cheiro de alimentos, visto que a lanchonete era no mesmo ambiente da recepção. A fim de minimizar o desconforto a que eram submetidos os pacientes, a Ouvidoria sugeriu a alteração da localização da lanchonete, e a proposta foi acatada.

Outro assunto tratado pela Ouvidoria foi a identificação de que o processo de limpeza dos quartos para a liberação da vaga para o próximo paciente era moroso no período de troca de turno, que coincidia com o horário de maior fluxo de saídas e entradas (altas e internações) de pacientes, e que, em alguns casos, havia necessidade de refazer o trabalho pela utilização indevida dos quartos por parte de alguns colaboradores do período noturno, que aproveitavam, de modo irregular, os leitos vazios para dormir. A partir do referido apontamento foi adotada a inserção de um lacre nos quartos limpos e alteração quanto aos horários de limpeza. Ainda sobre o procedimento de falta de leitos e a ideia equivocada de que se tratava de um problema de estrutura e não de processos operacionais, de posse de informações foi possível à Ouvidoria identificar que o cirurgião responsável 
por um expressivo percentual das internações diárias tinha como rotina realizar os procedimentos cirúrgicos pela manhã e somente passava em visita os pacientes internados para a deliberação da alta hospitalar depois de realizar todas as cirurgias eletivas, ou seja, se a rotina dele fosse invertida e iniciasse o trabalho do dia liberando os indicados para alta hospitalar, os pacientes submetidos à cirurgia no dia corrente teriam um quarto disponível com a devida brevidade. Essa análise foi apresentada em reunião com presença de todos os diretores do hospital, no entanto, possivelmente por se tratar de comportamento médico, não houve êxito quanto à sugestão para que o cirurgião iniciasse o dia realizando as altas.

Os cases inicialmente mencionados referem situações que, a partir da observação de reincidência de reclamações, ainda que em sua maioria identificadas como demanda improcedente na análise pontual, chamaram a atenção da Ouvidora, motivando uma análise minuciosa, que culminou em mudanças que representaram melhorias significativas nos resultados.

A seguir serão mencionados cases de situações em que ficam evidenciadas ações para disseminação da cultura de Ouvidoria, visando à mudança de paradigma e melhoria no relacionamento com as áreas.

A prática de dificultar o bom relacionamento com a Ouvidoria, por entender que é apenas um setor que só serve para apontar problemas, ou negligenciar as respostas das demandas, seja no seu conteúdo ou no cumprimento do prazo, é infelizmente uma atitude comum entre os responsáveis pelas áreas das instituições. Atuando em Ouvidoria de Concessionária de Rodovias foi possível trabalhar a disseminação da cultura de Ouvidoria, possibilitando aos responsáveis pelas áreas entender o seu significado, para que serve e como pode ser utilizada pelos gestores para otimizar resultados. Tal fato foi concretizado por intermédio da realização de um treinamento que enfatizou os esclarecimentos sobre o trabalho da Ouvidoria e, em contrapartida, buscou sensibilizar os colaboradores trazendo exemplos práticos sobre o quanto a demora em responder às manifestações ou mesmo a negligência quanto aos subsídios oferecidos pode impactar negativamente toda a instituição, causando retrabalho tanto para a Ouvidoria quanto para as áreas envolvidas, principalmente ocasionando a insatisfação dos usuários. Através de uma dinâmica simples (montagem de um quebra-cabeça), os participantes do treinamento puderam compreender o quanto uma resposta evasiva causa retrabalho. Nessa dinâmica os participantes eram convidados a montar um quebra-cabeça e imaginar que ele era uma demanda da Ouvidoria; nesse sentido, era informado um tempo para conclusão e então a montagem começava. A certa altura, descobriam que faltava uma peça e eram orientados pela Ouvidora a buscá-la na recepção; enquanto saíam para buscar a peça, a Ouvidora desmontava tudo e, quando eles retornavam com um envelope que acreditavam conter a peça que faltava, descobriam um bilhete informando que o tempo todo a peça estava com a Ouvidora. Nesse momento recebiam a peça faltante, entretanto, eles tinham que reiniciar a montagem, fato que causava grande desconforto, decorrente do excessivo dispêndio de tempo e retrabalho. Ao final da atividade não foi necessário explicar a moral da história, os próprios participantes mencionavam o quão desagradável e desgastante era o retrabalho criado pelo próprio responsável pela área, que desde o início já tinha condições de dar a informação completa e não procedia dessa forma. Como resultado do treinamento houve melhoria imediata na qualidade das respostas das demandas.

No tocante à ideia equivocada de que a Ouvidoria serve apenas para apontar problemas, outro 
case interessante ocorrido em concessionária de rodovias foi quando a Ouvidora se propôs a passar 24 horas literalmente rodando pela rodovia com veículos de inspeção (guincho), acompanhando o procedimento para entender melhor o processo operacional e para formulação de sugestões. Ao retornar da experiência in loco foi elaborado um relatório evidenciando os pontos fortes e fracos, oportunidades e ameaças, que foi positivamente recebido pela diretoria e gestores, que adotaram algumas das ações de melhoria propostas pela Ouvidora, como chamar o usuário da rodovia pelo nome ao aproximar-se para atendê-lo. Essa ideia surgiu ao observar que um dos colaboradores do guincho fazia isso e a reação dos usuários ao serem tratados pelo nome era muito boa, mesmo que estivessem esperando pelo atendimento há algum tempo, pois dessa forma se sentiam respeitados. Diante disso, o Centro de Controle Operacional foi orientado a sempre informar aos inspetores o nome do usuário que estavam indo atender para que, na abordagem inicial, o colaborador o tratasse pelo nome. Outro ponto observado foi quanto à dificuldade nos períodos de intervalo dos colaboradores, que muitas vezes eram interrompidos em seu período de descanso para realizar atendimentos de emergência. Tal fato também foi reavaliado pelos gestores, e as melhorias realizadas representaram maior satisfação dos colaboradores e, como consequência, dos usuários. A concessionária em questão, no ano de 2018, na pesquisa de satisfação no tocante ao atendimento do guincho, ocupou o primeiro lugar no ranking em comparação com as demais concessionárias submetidas à pesquisa.

\section{CONSIDERAÇÕES FINAIS}

O trabalho da Ouvidoria tem cada vez mais conquistado espaço dentro das instituições. Empresas que entendem a existência da área como algo muito maior do que o simples cumprimento de uma exigência normativa, vislumbrando o potencial da Ouvidoria como ferramenta de gestão estratégica, têm se destacado no mercado.

Instituições que adotam a Ouvidoria como "termômetro" para a tomada de decisões, aproveitando as informações registradas (indicadores) e as recomendações apresentadas pelos Ouvidores para mudanças e/ou melhorias, são capazes de otimizar resultados realizando ações muitas vezes aparentemente simples e óbvias aos olhos do cliente, mas que na visão da instituição não seriam possíveis sem a atuação e intervenção do Ouvidor para apresentar à diretoria a expectativa e a percepção do cliente.

O presente artigo relata alguns exemplos de situações em que a Ouvidoria agiu de forma proativa "provocando mudanças" independentemente do fato de haver uma demanda de reclamação procedente, apenas considerando que a insatisfação do cliente por si só sobre um assunto é motivo para revisitar processos, e a proposta ao leitor é levantar reflexões sobre sua atuação profissional e sobre quais são suas principais formas de apresentar à diretoria a expectativa e percepção do cliente e sugerir melhorias. 


\section{REFERÊNCIAS}

ASSOCIAÇÃO BRASILEIRA DE OUVIDORES. Disponível em: <http://www.abonacional.org.br/>. Acesso em: 10 jul. 2014.

BERRY, Leonard L. Serviços de satisfação máxima: guia prático de ação. Rio de Janeiro: Campus, 1996.

BHOTE, Keki R. Qualidade de classe mundial: usando o projeto de experimentos para melhoria. Rio de Janeiro: Qualitymark, 1992.

CLASSIFICAÇÃO BRASILEIRA DE OCUPAÇÕES. Disponível em: <http://www.mtecbo.gov.br/cbosite/pages/pesquisas/BuscaPorTitulo.jsf>. Acesso em: 20 jun. 2019.

MAXIMIANO, Antonio Cesar Amaru. Teoria Geral da Administração: Da Revolução Urbana à Revolução Digital. 7. ed. São Paulo: Atlas, 2012.

PALADINI, Edson Pacheco. Gestão estratégica da qualidade: princípios, métodos e processos. 2. ed. São Paulo: Atlas, 2009.

PEREZ, José Roberto Rus; BARREIRO, Adriana Eugênia Alvim; PASSONE, Eric. Construindo a Ouvidoria no Brasil: avanços e perspectivas. Campinas: Unicamp, 2011.

SÁ, Adísia; VILANOVA, Fátima; MACIEL, Roberto. Ombudsman, Ouvidores: transparência, mediação e cidadania. Fortaleza: Edições Demócrito Rocha, 2004.

SERTEK, Paulo; GUINDANI, Roberto Ari; MARTINS, Tomas Sparano. Administração e Planejamento estratégico. 3. ed. Curitiba: IBPEX, 2011.

SILVA, Helizena Celestino. Modelo de implantação de Ouvidoria. Bauru: Unesp, 2014. 